\title{
Assessing the Condition of Reinforced Concrete Bridge Using Visual Inspection Ratings
}

\author{
Abdoul S. Bah ${ }^{1}$, Thomas Sanchez ${ }^{1}$, Yan Zhang ${ }^{2}$, Kotaro Sasai ${ }^{2}$, David Conciatori ${ }^{1}$, Luc \\ Chouinard $^{2}$, Gabriel J. Power ${ }^{3}$ and Nicolas Zufferey ${ }^{4}$ \\ Research Center on Concrete Infrastructure (CRIB), Dept. of Civil and Water Engineering, \\ Université Laval, Québec, QC, G1V 0A6, Canada, david.conciatori@gci.ulaval.ca \\ ${ }^{2}$ Centre d'Études Interuniversitaire des Structures sous Charges Extrême (CEISCE), Dept. of Civil \\ Engineering, McGill University, Montreal, QC, H3A OC3, Canada, luc.chouinard@mcgill.ca \\ Research Center on Concrete Infrastructure (CRIB), Dept. of Finance, Insurance and Real Estate, \\ Université Laval, Québec, QC, G1V 0A6, Canada, gabriel.power@fsa.ulaval.ca \\ ${ }^{4}$ Geneva School of Economics and Management (GSEM), University of Geneva, 1211 Geneva 4, \\ Switzerland,n.zufferey@unige.ch
}

\begin{abstract}
The evolution of the state of a structure is characterized by deterioration. This is mainly due to corrosion of the steel reinforcement and damage from mechanical solicitations. The maintenance of existing infrastructures involves a good grasp of their condition and a high level of expertise on the part of the project managers. An accurate assessment of the bridge state condition is required to plan maintenance and repair activities for better durability, and to maintain the level of service of the road network. In this paper, an effective management framework for bridge is proposed using field observations from visual inspections. Each element of the bridge was evaluated separately by a visual inspection from which were derived ratings to quantify the structural performance and the material condition. The element ratings were also combined to obtain an overall rating for the bridge considering its defects and impact on the behavior of the complete structure. The modelling approach proposed in this work can better represent the deterioration of concrete-built bridges when the defect is visible. A representative structure in Quebec was studied to illustrate how to apply the methodology for the assessment of a real structure condition at specific times.
\end{abstract}

Keywords: Concrete, Bridge, State, Assessment, Durability.

\section{Introduction}

The main cause of deterioration of road structures in cold regions is steel rebar corrosion in concrete with the presence of chloride ions (Conciatori, et al., 2018; Roelfstra, et al., 2004).

However, using de-icing salts during winter, due to the microclimate, problematic for the safety of structures (Angst, 2019). For example, there are 614,387 bridges in the USA, among which 56,007 were structurally deficient in 2016. Most bridges have been designed for a 50year service life, but nearly $40 \%$ of them are more than 50 years old. Currently, the average age of those bridges is 43 years. Around 188 million users cross a structurally deficient bridge every day. The latest estimations bring the backlog of bridge rehabilitation needs in the USA to $\$ 123$ billion (ASCE, 2017). In Canada, 60\% of structures in the national highway network will be 
more than 40 years old in 2020. The number of bridges built more than 50 years ago, has increased by $50 \%$ since 2010 (RRN, 2010). Usually, repair works are done each 30 years period.

For the next few years, maintenance and repair needs in Quebec, Canada will reach a high level. The setting of Quebec is interesting because it is a Nordic climate where the challenges of a cold, harsh winter, de-icing, etc. are significant.

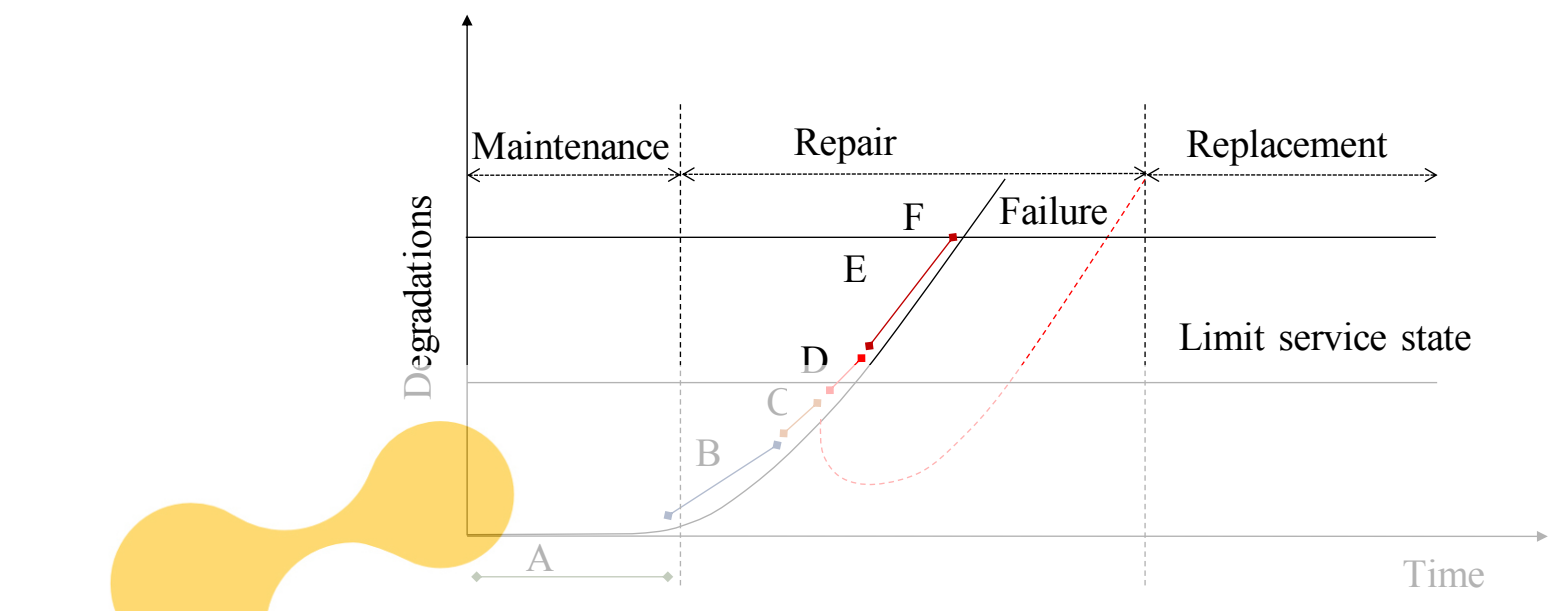

Figure 1. Evolution of the deterioration state of a reinforced concrete bridge: A: Very good; B: Good; C: Satisfactory; D: Bad; E: Very bad; F: Failure.

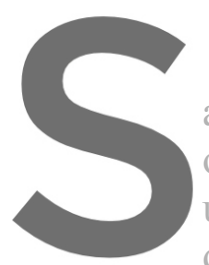

Monitoring the state activities. These activiti

of users and goods. Historical ar

used to predict future bi

deterioration thanks
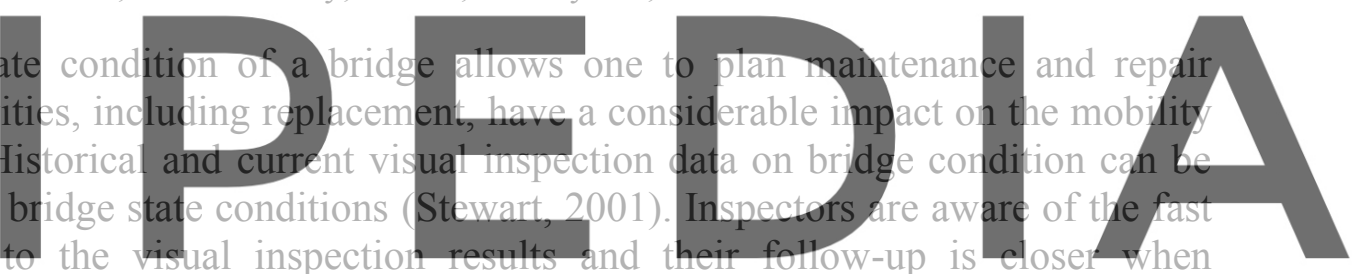

degradation appears for the sensitive structural elements. Detailed historical inspection reports

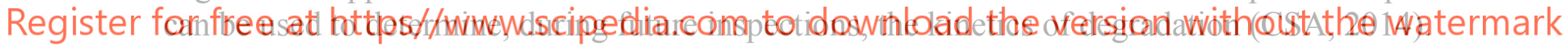

The evolution of the deterioration state of a reinforced concrete bridge and its rehabilitation can be represented with the state index indicator (Figure 1). A, B and C ratings mean very good, good and satisfactory conditions, respectively. D and E ratings are bad and very bad conditions, respectively (MTQ, 2018). The fundamental interest of a project manager is to understand perfectly the permissible service and failure limit states in order to plan appropriate repair activities (Ter Berg, et al., 2019). Sustainability and resilience concepts for infrastructure systems are important for the community. Consequently, both of these concepts need to be integrated at the level of the infrastructure assessment to accurately determine the performance criteria of an infrastructure (Lounis and McAllister, 2016). This allows to consider the acceptable risk of service failure to minimize the consequences associated with the different limit states such as: accidents, interruptions of service to users and repair costs (Adey, et al., 2003).

In this paper, a new approach to assess the condition of a typical structure is proposed. The methodology has been applied on a 60 year reinforced concrete bridge in Quebec (Figure 2). 

and Nicolas Zufferey

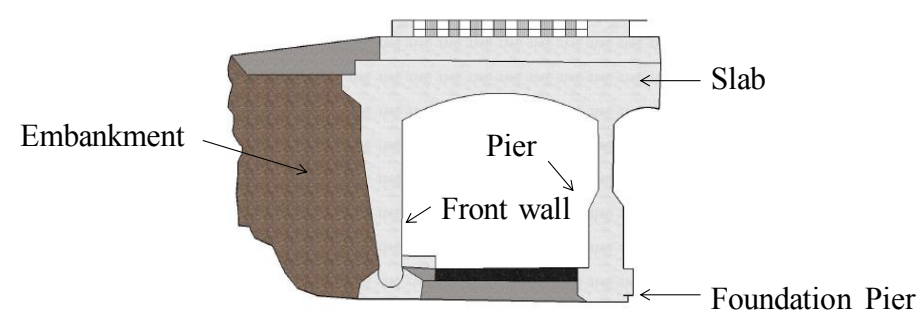

Figure 2. Half profile of the bridge (Quebec).

The bridge consists of a portico with two symmetrical spans (the free span is $11.4 \mathrm{~m}$ ). The deck is a thick slab kind. Its thickness at the level of the supports is $1 \mathrm{~m}$ and its thickness at the centre is $0.60 \mathrm{~m}$. The extremity supports and the central pier are continuous over the full width of the structure. It has four traffic lanes. The closure would cause significant inconvenience for the users which access to the lower four lanes under the bridge. This paper focuses on the degradation analysis process and the bridge assessment. This approach introduces a new management methodology for making an optimal and sustainable decision for bridge maintenance.

\section{Degradation Analysis Process}

A visual inspection of this bridge allowed us to evaluate its material and structural behavior state. The defects were identified dyring the visual inspection precess, following the methodology in the inspection manual of the 'Ministère des Transports du Québec'(MTQ. 2017). The objective of the experimental procedure was to assess separately by the visua
inspection method: (i) the material deterioration and (ii) the structural behavior of the bridge.

The purpose of material condition assessment is to provide with $2 \mathrm{n}$ assessment of the material defects detected on an element. To do this, four states $(\alpha, \beta, \gamma, \delta)$ are defined, Register for free at http seyerity levels observed: nf deterioration moderate deterioration sionificant deterioration, and very significant deterioration, respectively. The structurat behavior evaluation rating of an element $i$ ( $b_{i}$ rating) gives an indication of the impact of defects on its structural capacity, functionality, stability, user comfort and safety. The behavior rating for each bridge element is estimated with a four degradation scale: $1 \rightarrow 4$ ( 1 being the worst and 4 the best behavior).

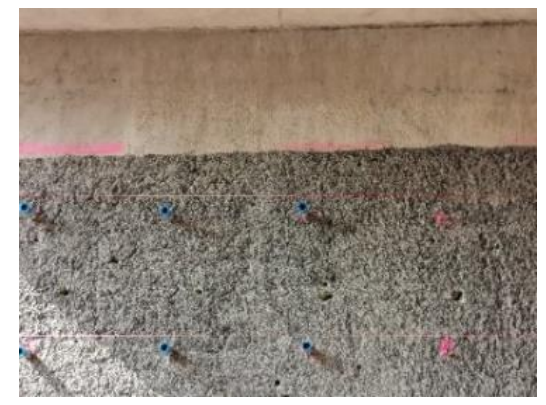

Figure 3. Visual inspection of the front wall of the bridge. 
The bridge was divided into elements, which were evaluated separately. As an example, the visual condition of the bridge front wall showed a reparation during the visual inspection (Figure 3).

Table 1. Visual inspection rating of material condition and behavior of the front wall of the bridge.

\begin{tabular}{cccccc}
\hline & \multicolumn{4}{c}{ Material (\%) } & Behavior \\
\hline Ratings & $\alpha$ & $\beta$ & $\gamma$ & $\delta$ & $\mathrm{b}_{\mathrm{i}}$ \\
\hline Front wall & 15 & 0 & 85 & 0 & 3 \\
\hline
\end{tabular}

The inspection report for the front wall showed: $\alpha=15 \%$ of the material has no deterioration and $\gamma=85 \%$ has to be repaired, and the structural behavior reaches a rating of $b_{i}=3$ because this defect affects appreciably the stability of the structure (Table 1). Similarly, the material and behavior defects for each element of the bridge were performed and presented in section 3 (Table 2).

The local rating on structural elements, as described above, allows one to identify the wrong behavior or a major deterioration on a part of the structure. This could provide the managers the idea to conduct some urgent local repair. However, structure managers are often interested to assess a global index of their structure. The global index allows managing the structure in the network scale and to plan its intervention agenda according to the whole network state, and with a minimum impact on the traffic. This global index gives an indication on the structural

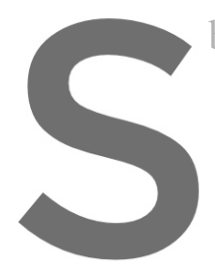
behavior and the matdina
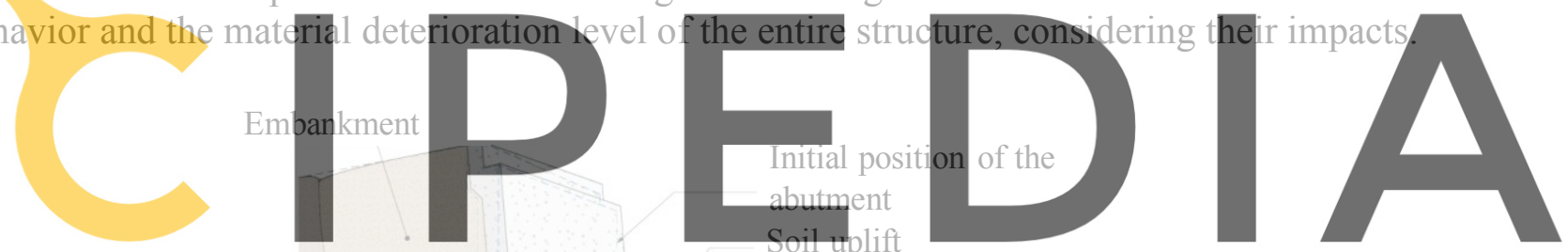

Register for free at https//www.scipedia.com to download the version without the watermark Soft soil

Sliding piane

Figure 4. Example of abutment failure links (MTQ, 2017).

The following model proposes an evaluation of the global index as defects of each element (rating of each element) and the impact of the default on the structure by a decision tree analysis. The element ratings are merged considering failure assignment links to obtain the bridge global rating. For example, an abutment with a soil failure links has a repercussion on the abutment foundation (Figure 4). Additionally, the abutment foundation has a repercussion on the bridge seat, and the bridge seat has a repercussion on the slab. Let $x_{i j}$ the defects affectation link between two elements $i$ and $j$,

- $x_{i j}=1$ when the degradation of an element $i$ directly affects the adjacent element $j$;

- $x_{i j}=0$ when there is no link between the defects of the adjacent elements $i$ and $j$. 
Abdoul S. Bah, Thomas Sanchez, Yan Zhang, Kotaro Sasai, David Conciatori, Luc Chouinard, Gabriel J. Power and Nicolas Zufferey

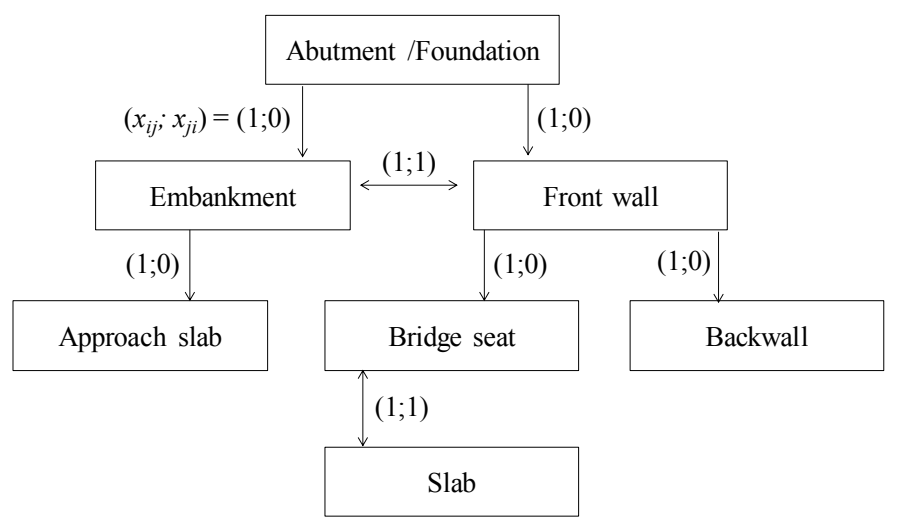

Figure 5. Failure links $\left(x_{i j} ; x_{j i}\right)$ for the abutment of the bridge.

In this way, $\left(x_{i j} ; x_{j i}\right)=(1 ; 0)$ when element $i$ is affected by element $j$ but a defect of element $j$ does not impact element $i$. Moreover, $\left(x_{i j} ; x_{j i}\right)=(1 ; 1)$ when the defect of element $i$ affects element $j$ and, conversely, a defect of element $j$ affects element $i$. The defect affectations of the bridge are given for the previous example with the abutment in Figure 5. This systematic approach is based on the qualitative and quantitative analysis of the visual inspection records. The parent-child principle, based on the decision tree analysis, enables to gradually identify the different links between the element failures at the local level. Thereafter, the bridge was assessed at the global level with different equations developed in the following section.

\section{Bridge Assessment}

For the bridge assessment, as initiated previously in section 2, scale at the level of the structural element, and

part, the rating of each element is calculated, and then a new model for assessing the material

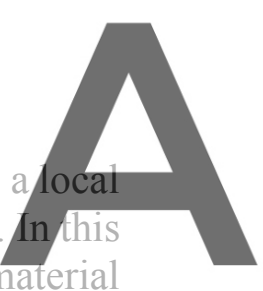
global index $I_{M}$ and the behavior condition $I_{B}$ of the bridge is proposed.A visual inspection was

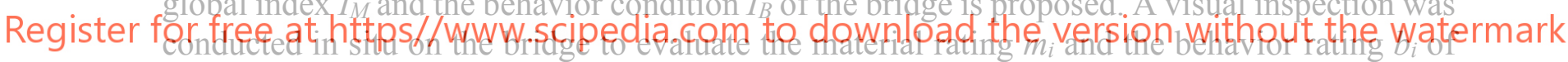
each element $i$. The visual inspection results for each bridge element are presented in Table 2. Some information is missing because the elements concerned were neither accessibie nor visible.

Table 2. Visual inspection rating of material condition and behavior of the first span of the bridge.

\begin{tabular}{ccccccc}
\hline Element & \multicolumn{4}{c}{ Material } & Behavior \\
\cline { 2 - 7 } & $\alpha$ & $\beta$ & $\sigma$ & $\delta$ & $\mathrm{m}_{\mathrm{i}}$ & $\mathrm{b}_{\mathrm{i}}$ \\
\hline Backfill Granular & & & & & & 4 \\
\hline $\begin{array}{c}\text { Foundation Prefabricated } \\
\text { concrete piles / abutment }\end{array}$ & & & & & & 4 \\
\hline $\begin{array}{c}\text { Front Wall } \\
\text { Foundation Prefabricated } \\
\text { concrete piles / Pier }\end{array}$ & $15 \%$ & 0 & $85 \%$ & 0 & 2 & 3 \\
\hline Pier/Barrel & $98 \%$ & 0 & $2 \%$ & 0 & 4 & 4 \\
\hline
\end{tabular}


Abdoul S. Bah, Thomas Sanchez, Yan Zhang, Kotaro Sasai, David Conciatori, Luc Chouinard, Gabriel J. Power and Nicolas Zufferey

\begin{tabular}{ccccccc}
\hline Running surface & $80 \%$ & $10 \%$ & $10 \%$ & 0 & 3 & 3 \\
\hline External side (North) & $95 \%$ & 0 & $5 \%$ & 0 & 4 & 3 \\
\hline External side (South) & $95 \%$ & 0 & $5 \%$ & 0 & 4 & 3 \\
\hline Deck Regular concrete slab & $99 \%$ & 0 & $1 \%$ & 0 & 4 & 4 \\
\hline Sidewalk (North) & $80 \%$ & $20 \%$ & 0 & 0 & 4 & 4 \\
\hline Sidewalk (South) & $20 \%$ & 0 & $80 \%$ & 0 & 2 & 2 \\
\hline Guardrails Other Models & $20 \%$ & $80 \%$ & 0 & 0 & 3 & 4
\end{tabular}

The four levels of material condition degradation ( $\alpha$ to $\delta$ ) were combined to obtain a single material rating $m_{i}$ for each element $i$ through equation (1):

$$
m_{i}=\sum_{j=1}^{4} \frac{P_{j, i}}{P_{1, i}+\cdots+P_{4, i}}(5-j) \text { with } P_{1, i}=\alpha_{i}^{\exp n_{(\alpha)}}, \ldots, P_{4, i}=\delta_{i}^{\exp n_{(\delta)}}
$$

$P$ is the deterioration penalty of the bridge element $i, n$ is the weight of the deterioration penalty, the exponential function represents a factor of the deterioration penalty, and $j$ is the deterioration level. In this study, $n$ is fixed for each level of degradation and defined such that the repair activities must be recommended for each element (Table 3) if at least one of the following conditions is true : $\delta>1 \% ; \beta>15 \%$ and $\gamma>13 \% ; \beta>45 \%$ and $\gamma=13 \% ; \beta=0$ and $\gamma \geq 15 \%$. Such conditions allow to consider the moderate degradations $\beta$ that are currently not considered by the traditional infrastructure managements
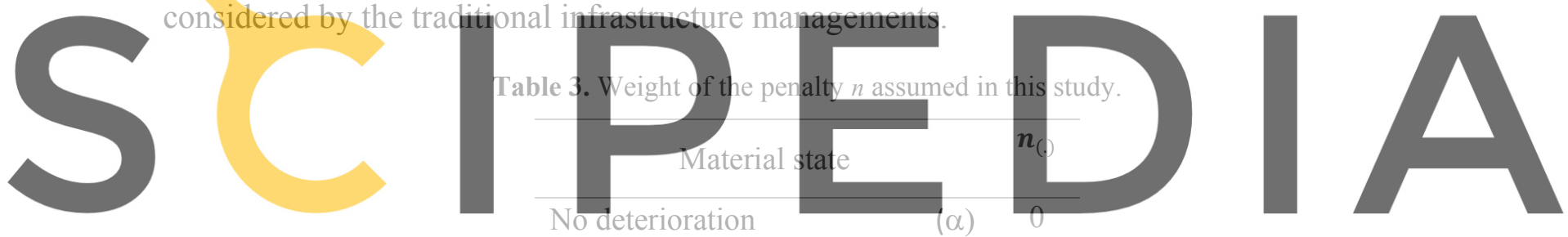

Register for free at https//www.scipedia.com to download the yersion without the watermark

$$
\text { Very significant deterioration }(\delta) \quad 2.5
$$

An example of the material rating calculation for the front wall of the bridge is illustrated by equation (2). $m_{i}$ was evaluated using the extended visual inspection in Table 1:

$$
m_{i}=\frac{15^{\exp 0}}{10,093} \cdot(5-1)+\frac{85^{\exp 0.73}}{10,093} \cdot(5-3) \approx 2
$$

Finally, the global index $I_{M}$ and $I_{B}$ are obtained from the rating $m_{i}$ and $b_{i}$ calculated for each element $i$ and from the global assignment links $\left(x_{i j} ; x_{j i}\right)$. Intermediate equations $R_{M}$ and $R_{B}$ were defined to simplify the expression of $I_{M}$ and $I_{B}$ such as:

$$
R_{M}=\sum_{i \epsilon W} A^{m_{i}} \sum_{j \epsilon W \backslash i} x_{i j} \text { and } R_{B}=\sum_{i \epsilon W} A^{b_{i}} \sum_{j \epsilon W \backslash i} x_{i j}
$$


where $W$ is the global assignment links and $A$ the factor of degradation evolution. $A$ was assumed to be equal to 5 in this paper (W.R. de Sitter, 1984). Thus,

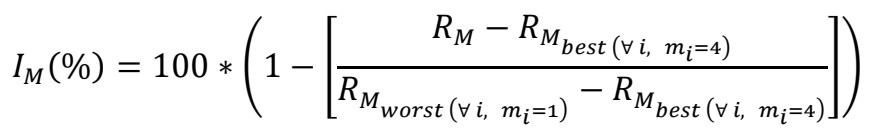

$$
\begin{aligned}
& I_{B}(\%)=100 *\left(1-\left[\frac{R_{B}-R_{B_{\text {best }}\left(\forall i, b_{i}=4\right)}}{R_{B_{\text {worse }}\left(\forall i, b_{i}=1\right)}-R_{B_{\text {best }}\left(\forall i, b_{i}=4\right)}}\right]\right)
\end{aligned}
$$

\section{Results and Discussions}

For the entire bridge, the results of the assessment model computations, based on the visual inspection, to assess its state condition are: $I_{M}=78.76 \%$ and $I_{B}=79.97 \%$ (Figure 6). The results of this model show that the deterioration level of the bridge, both in material and behavior is lower than the maximum accepted limit of $80 \%$ defined by public sector managers. For structures in good condition, maintenance is recommended between 75 and $80 \%$ as soon as possible. The present model allows one to provide advice for a maintenance to avoid further major repairs. However, using a model only based on visual inspection can only identified most obvious visible deteriorations (identified by C, D and E phases in Figure 1). The early signs of

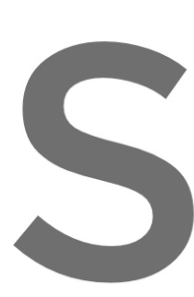
deteriorations, such as inspections to prevent the efficiency.

Register for free at https//www.scipedia.com to download the
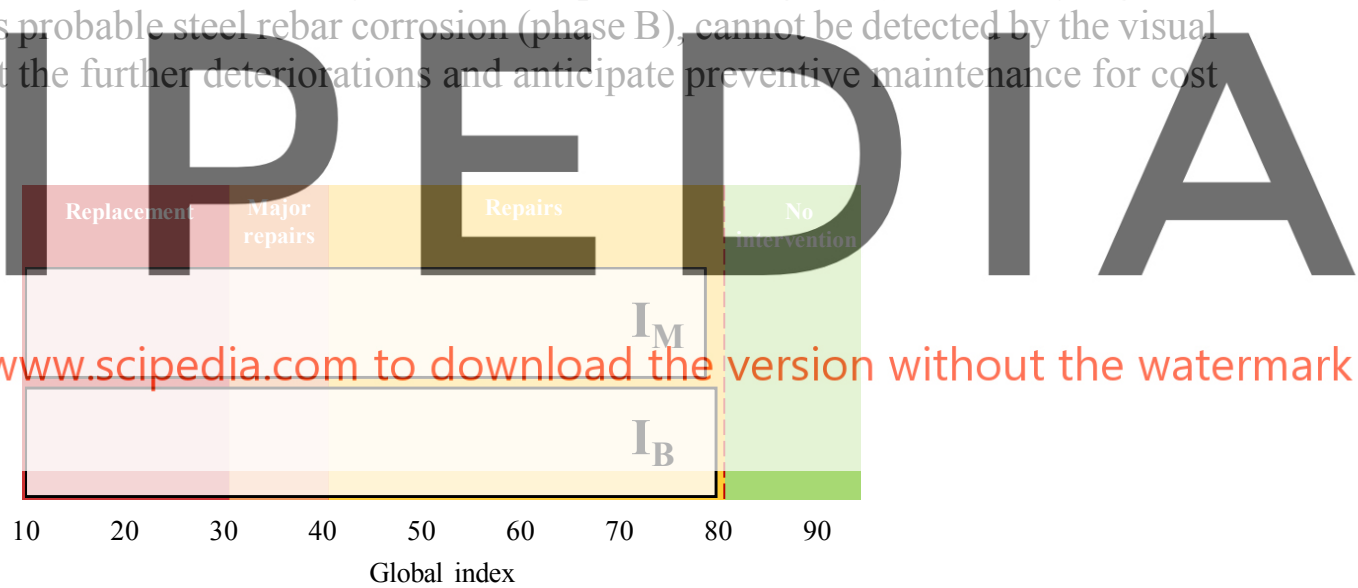

Figure 6. Bridge behavior and material condition by visual inspection.

\section{Conclusion}

The challenge for maintaining existing infrastructure plays an important role in a country's economical and social activities. This paper addresses the assessment of a bridge condition focusing on the resilience of each element at the local level to achieve a significant benefit at the global level of the bridge based on the visual inspection. The developed visual inspection model incorporates (in the assessment) the effects of moderate degradations, which are generally ignored by inspection managers. The consideration of those degradation levels revealed that the bridge needs maintenance. As a result, this assessment model based on visual 
inspections allows to improve the degradation rating used by traditional public managers.

However, the uncertainty on the physical and chemical degradation observed by visual inspection have an important impact on the computation of the material and behavior indices. Further works in progress will improve the assessment of the bridge state condition by coupling the visual inspection model presented in this paper with a deterioration prediction model. This approach will refine the deterioration assessment to the early state phases (A and B phases in Figure 1) to forecast preventive maintenances.

\section{Acknowledgements}

The authors gratefully acknowledge the "Islamic Development Bank", "Fonds de recherche du Québec - Nature et technologies" for their financial support. The authors also want to thank "Service des infrastructures, de la voirie et des transports" of the city of Montreal and the "Quebec Ministry of Transportation" for their collaboration.

\section{ORCID}

Abdoul S. Bah: https://orcid.org/0000-0001-9245-9000

Thomas Shanchez: https://orcid.org/0000-0002-5929-7449

Yan Zhang: https://orcid.org/0000-0002-3222-2340

Kotaro Sasai: https://orcid.org/0000-0003-4483-5280

David Conciatori: https://orcid.org/0000-0002-1187-4868

Nicolas Zufferey: https://orcid.org/0000-0002-5500-010X

References

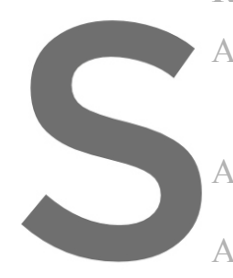

Adey, B., Hajdin, R. and Management Stra $-0342(2003) 9: 3($

Angst, U. M. (2019). Pr chlorides. Cement

ASCE. (2017). Infrastructure R
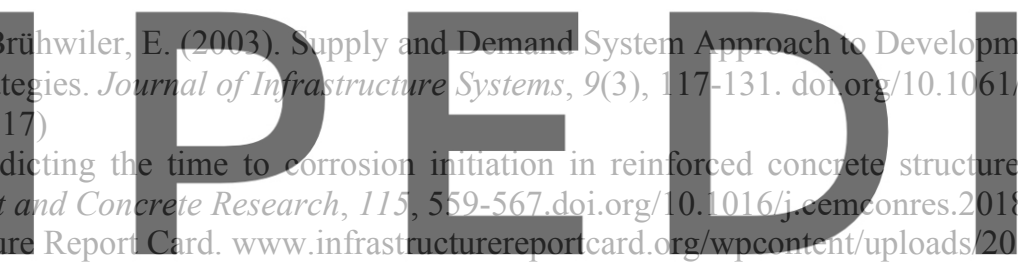
1 Infrastructure-Report Card.pdf

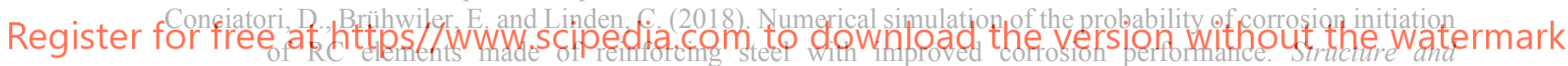
Infrastructure Engineering, O(0), 1-9. doi:10.1080/15732479.2018.1446180

CSA. (2014). S6-14 Code canadien sur le calcul des ponts routiers. store.csagroup.org/

Lounis, Z. and McAllister, T. P. (2016). Risk-Based Decision Making for Sustainable and Resilient Infrastructure Systems. Journal of Structural Engineering, 142(9), F4016005. doi.org/10.1061/(ASCE)ST.1943541X.0001545

MTQ. (2017). Manuel d'inspection des structures. www3.publicationsduquebec.gouv.qc.ca > guides >guide24.fr. MTQ. (2018). Bilan de l'état des structures. www.transports.gouv.qc.ca/fr

Roelfstra, G., Hajdin, R., Adey, B. and Brühwiler, E. (2004). Condition Evolution in Bridge Management Systems and Corrosion-Induced Deterioration. Journal of Bridge Engineering, 9(3), 268-277. doi.org/10.1061/(ASCE)1084-0702(2004)9:3(268)

RRN. (2010). Réseau Routier National du Canada. www.bv.transports.gouv.qc.ca/per/1018796/04_2010.pdf

Stewart, M. G. (2001). Effect of Construction and Service Loads on Reliability of Existing Rc Buildings. Journal of Structural Engineering, 127(10), 1232. doi.org/10.1061/(ASCE)0733-9445(2001)127:10(1232)

Ter Berg, C. J. A., Leontaris, G., van den Boomen, M., Spaan, M. T. J. and Wolfert, A. R. M. (2019). Expert judgement based maintenance decision support method for structures with a long service-life. Structure and Infrastructure Engineering, 1-12. https://doi.org/10.1080/15732479.2018.1558270

W.R. de Sitter. (1984). Costs of service life optimization « The Law of Fives » CEB-RILEM Workshop on Durability of Concrete Structures (Copenhagen, Denmark, May 18-20, 1983). 